\title{
$\underline{\mathbf{P}-82}$
}

\section{Synthesis of 4-Methoxybenzoylhydrazone Derivatives and Evaulation of Their Antiglycation Activity}

\author{
A'qilah Abd Rahman ${ }^{1,3}$, Muhammad Taha ${ }^{1, *}$, Humera Naz ${ }^{1,3}$, Nor Hadiani Ismail ${ }^{2}$, Saima Rashid ${ }^{4}$ \\ and M. Iqbal Choudhary ${ }^{4}$ \\ ${ }^{I}$ Atta-ur-Rahman Institute for Natural Product Discovery, Universiti Teknologi MARA, Puncak Alam Campus, 42300 \\ Bandar Puncak Alam, Selangor D. E. Malaysia; ${ }^{2}$ Faculty of Applied Science Universiti Teknologi MARA, 40450 Shah \\ Alam; ${ }^{3}$ Faculty of Pharmacy, Universiti Tecknologi MARA, Puncak Alam 42300, Selangor, Malaysia; ${ }^{4}$ H.E.J. Research \\ Institute of Chemistry, International Center for Chemical and Biological Sciences, University of Karachi, Karachi- \\ 75270,Pakistan; E-mail: taha_hej@yahoo.com
}

4-Methoxybenzoylhydrazone derivatives (1-30) were synthesized from 4-methoxybenzoylhydrazide which were obtained from methyl-4-methoxybenzoate by refluxing with hydrazine hydrate for $5 \mathrm{~h}$. 4-Methoxybenzoylhydrazones derivatives were prepared by condensing 4-methoxybenzoylhydrazide with different aromatic aldehydes under reflux condition in ethanol for 3$4 \mathrm{~h}$. The compounds 1-30 showed varying degree of antiglycation activitiy, with $\mathrm{IC}_{50}$ values ranging between $216.52 \pm 4.2$ $748.71 \pm 7.8 \mu \mathrm{M}$, when compared to standard Rutin $(294.46 \pm 1.50 \mu \mathrm{M})$. Compounds $\mathbf{1 , ~ 6 , ~ 7 , ~} 11$ and $\mathbf{3}\left(\mathrm{IC}_{50}=216.52 \pm 4.2\right.$ $\mu \mathrm{M}),\left(\mathrm{IC}_{50}=227.75 \pm 0.53 \mu \mathrm{M}\right),\left(\mathrm{IC}_{50}=242.53 \pm 6.1 \mu \mathrm{M}\right),\left(\mathrm{IC}_{50}=287.79 \pm 1.59 \mu \mathrm{M}\right)$, and $\left(\mathrm{IC}_{50}=289.58 \pm 2.64 \mu \mathrm{M}\right)$ showed better activities than standard Rutin $(294.46 \pm 1.50 \mu \mathrm{M})$. The compounds $\mathbf{4 , 8}, \mathbf{2}$ and $\mathbf{1 2}\left(\mathrm{IC}_{50}=307.1 \pm 6.08 \mu \mathrm{M}\right),\left(\mathrm{IC}_{50}=\right.$ $347.62 \pm 5.8 \mu \mathrm{M}),\left(\mathrm{IC}_{50}=394.76 \pm 3.35 \mu \mathrm{M}\right)$ and $\left(\mathrm{IC}_{50}=399.90 \pm 7.9 \mu \mathrm{M}\right)$ showed good activity. The compounds 5 and 17 $\left(\mathrm{IC}_{50}=420.40 \pm 3.3 \mu \mathrm{M}\right)$, and $\left(\mathrm{IC}_{50}=474.97 \pm 19.14 \mu \mathrm{M}\right)$ showed moderate activities. The compounds 14, 10, 18 and $15\left(\mathrm{IC}_{50}\right.$ $=649.18 \pm 18.5 \mu \mathrm{M}),\left(\mathrm{IC}_{50}=657.75 \pm 14.0 \mu \mathrm{M}\right),\left(\mathrm{IC}_{50}=718.96 \pm 10.7 \mu \mathrm{M}\right)$, and $\left(\mathrm{IC}_{50}=748.71 \pm 7.8 \mu \mathrm{M}\right)$ showed weak activities. The compounds $\mathbf{9 , 1 3}$ and 18-30 showed inhibition less than $50 \%$ therefore they were not evaluated for $\mathrm{IC}_{50}$. Thus, these compounds are potential molecules for the development of new derivatives for glycation inhibition.

Keywords: 4-Methoxybenzoylhydrazide, antiglycation, AGEs, diabetes, Maillard reaction. 